\title{
Sensitivity of Nanostructured Iron Metal on Ultrasonic Properties
}

\author{
Alok Kumar Gupta ${ }^{1}$, Archana Gupta ${ }^{2}$, Devraj Singh ${ }^{3 *}$, Sudhanshu Tripathi ${ }^{4}$ \\ ${ }^{1}$ Academic Department, National Institute of Open Schooling (NIOS), \\ Ministry of HRD, Govt. of India, Noida, India \\ ${ }^{2}$ Department of Biochemistry, University of Lucknow, Lucknow, India \\ ${ }^{3}$ Department of Applied Sciences, Amity School of Engineering and Technology, New Delhi, India \\ ${ }^{4}$ Department of Instrumentation and Control Engineering, Amity School of Engineering and Technology, \\ New Delhi, India \\ E-mail:"dsingh1@aset.amity.edu
}

Received October 20, 2011; revised November 14, 2011; accepted December 2, 2011

\begin{abstract}
The present investigation is focused on the influence of the nanocrystalline structure of pure iron metal on the ultrasonic properties in the temperature range $100-300 \mathrm{~K}$. The ultrasonic attenuation due to phononphonon interaction and thermoelastic relaxation phenomena has been evaluated for longitudinal and shear waves along $\langle 100\rangle,\langle 110\rangle$ and $<111>$ crystallographic directions. The second-and third-order elastic constants, ultrasonic velocities, thermal relaxation, anisotropy and acoustic coupling constants were also computed for the evaluation of ultrasonic attenuation in this temperature scale. The direction $<111>$ is most appropriate to study longitudinal sound waves, while $\langle 100\rangle,<110>$ direction are best to propagate shear waves due to lowest values of attenuation in these directions. Other physical properties correlated with obtained results have been discussed.
\end{abstract}

Keywords: Iron Metal, Elastic properties, Ultrasonic Attenuation

\section{Introduction}

Nanocrystalline materials containing fine grains of nanometer sizes exhibit the very unique physical properties, which contrast with the corresponding polycrystalline and amorphous materials. The ultrasonic attenuation proved to be a precise tool to investigate variations in the microstructure of solids [1,2]. Ultrasonic velocity and attenuation studies have been made in solids [3-5], liquids [6,7], and liquid crystals $[8,9]$. A number of books and review articles are available which gives experimental techniques and theoretical interpretation. In solids $[10,11]$ there are several causes of ultrasonic attenuation, the most important being electron-phonon interaction at low temperatures $[12,13]$ and phonon-phonon interaction at high temperatures [14, 15]. There are several methods for theoretical evaluation of ultrasonic attenuation, but the most accepted and reliable one uses second and third order elastic constants (SOEC and TOEC) $[10,11]$.

Iron is a very important metal for industrial and domestic applications. We have chosen iron for the study to clarify their nature up to room temperature $\left(27^{\circ} \mathrm{C}=300^{\circ} \mathrm{K}\right)$. The application, quality control and assurance can be well understood with the knowledge of ultrasonic properties and related parameters. So, we studied the same properties for non-destructive characterization of iron in the temperature range between 100 and $300 \mathrm{~K}$.

In present investigation, we made an attempt to apply theoretical approach to find ultrasonic properties of iron by means of SOEC and TOEC along $\langle 100\rangle,\langle 110\rangle$, $<100>$ directions in the temperature regime $100-300 \mathrm{~K}$.

\section{Theoretical Approach}

Theory is categorized in two phases: in primary phase, we discussed the temperature dependence of SOEC and TOEC, while the attenuation of ultrasound due to phonon-phonon interaction and thermoelastic relaxation mechanisms with allied parameters has been explained in secondary phase.

SOEC and TOEC at absolute zero have been obtained following Brugger's definition [16] of elastic constant 
using Born-Mayer potential [17]. According to the anharmonic theory of lattice dynamics, the lattice energy of the single crystal changes with temperature $[18,19]$. Hence an addition of vibrational contribution to the elastic constants at absolute zero provides SOEC and TOEC at desired temperature.

$$
\mathrm{C}_{\mathrm{IJK} \ldots \ldots}=\mathrm{C}_{\mathrm{IJK} \ldots . . .}^{0}+\mathrm{C}_{\mathrm{IJK} \ldots \ldots .}^{\mathrm{Vib} .}
$$

where $\mathrm{C}_{\mathrm{IJK}}^{0}$ and $\mathrm{C}_{\mathrm{IJK}}^{\mathrm{Vib} . . .}$ represent static and vibrational elastic constants respectively. The expressions for $\mathrm{C}_{\mathrm{IJK} \ldots . .}^{0}$ and $\mathrm{C}_{\mathrm{IJK} . . .}^{\mathrm{Vib} .}$ are given below.

$$
\left.\begin{array}{rl}
\mathrm{C}_{11}^{0}= & \frac{3}{2} \frac{\mathrm{e}^{2}}{r_{0}^{4}} S_{5}^{(2)}+\frac{1}{b r_{0}}\left(\frac{1}{r_{0}}+\frac{1}{b}\right) \phi\left(r_{0}\right) \\
& +\frac{2}{b r_{0}}\left(\frac{\sqrt{2}}{2 r_{0}}+\frac{1}{b}\right) \phi\left(\sqrt{2} r_{0}\right) \\
\mathrm{C}_{12}^{0}= & C_{44}^{0}=\frac{3}{2} \frac{\mathrm{e}^{2}}{r_{0}^{4}} S_{5}^{(1,1)}+\frac{1}{b r_{0}}\left(\frac{\sqrt{2}}{2 r_{0}}+\frac{1}{b}\right) \phi\left(\sqrt{2} r_{0}\right) \\
\mathrm{C}_{111}^{0}= & -\frac{15}{2} \frac{\mathrm{e}^{2}}{r_{0}^{4}} S_{7}^{(3)} \\
& -\frac{1}{b}\left(\frac{3}{r_{0}^{2}}+\frac{3}{b r_{0}}+\frac{1}{b^{2}}\right) \phi\left(r_{0}\right) \\
& -\frac{1}{2 b}\left(\frac{3 \sqrt{2}}{r_{0}^{2}}+\frac{6}{b r_{0}}+\frac{2 \sqrt{2}}{b^{2}}\right) \phi\left(\sqrt{2} r_{0}\right) \\
\mathrm{C}_{112}^{0}= & \mathrm{C}_{166}^{0} \\
= & -\frac{15}{2} \frac{\mathrm{e}^{2}}{r_{0}^{4}} S_{7}^{(2,1)} \\
& -\frac{1}{4 b}\left(\frac{3 \sqrt{2}}{r_{0}^{2}}+\frac{6}{b r_{0}}+\frac{2 \sqrt{2}}{b^{2}}\right) \phi\left(\sqrt{2} r_{0}\right) \\
\mathrm{C}_{123}^{0}= & \mathrm{C}_{144}^{0}=\mathrm{C}_{456}^{0}=-\frac{15}{2} \frac{\mathrm{e}^{2}}{r_{0}^{4}} S_{7}^{(1,1,1)}
\end{array}\right\}
$$

where $r_{0}$ is the short range parameter; $b$ is hardness parameter; $\varphi\left(r_{0}\right)$ is the Born-Mayer potential given by $\phi\left(r_{0}\right)=A$ exp. $\left(-r_{0} / b\right)$ and $\phi\left(\sqrt{2} r_{0}\right)=A$ exp. $\left(-\sqrt{2} r_{0} / b\right)$; $\mathrm{A}$ is the strength parameter given by

$$
\begin{array}{ll}
A=-3 b \mathrm{~S}_{3}^{(1)} & \frac{\mathrm{e}^{2}}{\mathrm{r}_{0}^{2}}\left[6 \exp .\left(-\rho_{0}\right)+12 \sqrt{2} \exp .\left(-\rho_{0} \sqrt{2}\right)\right]^{-1}, \\
\rho_{0}=r_{0} / b . & \\
& \left.\begin{array}{l}
\mathrm{C}_{11}^{\text {Vib. }}=\mathrm{f}^{(1,1)} \mathrm{G}_{1}^{2}+\mathrm{f}^{(2)} \mathrm{G}_{2} \\
\mathrm{C}_{12}^{\text {Vib. }}=\mathrm{f}^{(1,1)} \mathrm{G}_{1}^{2}+\mathrm{f}^{(2)} \mathrm{G}_{1,1} \\
\mathrm{C}_{44}^{\text {Vib. }}=\mathrm{f}^{(2)} \mathrm{G}_{1,1}
\end{array}\right\}
\end{array}
$$

$$
\begin{aligned}
& \mathrm{C}_{111}^{\mathrm{Vib} .}=\mathrm{f}^{(1,1,1)} \mathrm{G}_{1}^{3}+3 \mathrm{f}^{(2,1)} \mathrm{G}_{1} \mathrm{G}_{2}+\mathrm{f}^{(3)} \mathrm{G}_{3} \\
& \mathrm{C}_{112}^{\mathrm{Vib}}=\mathrm{f}^{(1,1,1)} \mathrm{G}_{1}^{3}+\mathrm{f}^{(2,1)} \mathrm{G}_{1}\left(2 \mathrm{G}_{1,1}+\mathrm{G}_{2}\right)+\mathrm{f}^{(3)} \mathrm{G}_{2,1} \\
& \mathrm{C}_{123}^{\mathrm{Vib}}=\mathrm{f}^{(1,1,1)} \mathrm{G}_{1}^{3}+3 \mathrm{f}^{(2,1)} \mathrm{G}_{1} \mathrm{G}_{1,1}+\mathrm{f}^{(3)} \mathrm{G}_{1,1,1} \\
& \mathrm{C}_{144}^{\mathrm{Vib}}=\mathrm{f}^{(2,1)} \mathrm{G}_{1} \mathrm{G}_{1,1}+\mathrm{f}^{(3)} \mathrm{G}_{1,1,1} \\
& \mathrm{C}_{166}^{\mathrm{Vib} .}=\mathrm{f}^{(2,1)} \mathrm{G}_{1} \mathrm{G}_{1,1}+\mathrm{f}^{(3)} \mathrm{G}_{2,1} \\
& \mathrm{C}_{456}^{\mathrm{Vib} .}=\mathrm{f}^{(3)} \mathrm{G}_{1,1,1}
\end{aligned}
$$

where $f^{(n)}$ and $\mathrm{G}_{\mathrm{n}}$ are given as

$$
\begin{aligned}
& \mathrm{f}^{(2)}= \mathrm{f}^{(3)}=\frac{\mathrm{h} \omega_{0}}{8 r_{0}^{3}} \operatorname{cothx} \\
& \mathrm{f}^{(1,1)}=\mathrm{f}^{(2,1)}=\frac{\mathrm{h} \omega_{0}}{96 r_{0}^{3}}\left(\frac{\mathrm{h} \omega_{0}}{2 \mathrm{kT} \sinh ^{2} \mathrm{x}}+\operatorname{cothx}\right) \\
& \mathrm{f}^{(1,1,1)}=\frac{\mathrm{h} \omega_{0}}{384 r_{0}^{3}}\left(\frac{\left(\mathrm{h} \omega_{0}\right)^{2} \operatorname{cothx}}{6(\mathrm{kT})^{2} \sinh ^{2} \mathrm{x}}+\frac{\mathrm{h} \omega_{0}}{2 \mathrm{kT} \sinh ^{2} \mathrm{x}}+\operatorname{cothx}\right) \\
& \mathrm{G}_{1}=2\left\{\left(2+2 \rho_{0}-\rho_{0}^{2}\right) \phi\left(\mathrm{r}_{0}\right)\right. \\
&\left.+2\left(\sqrt{2}+2 \rho_{0}-2 \rho_{0}^{2}\right) \phi\left(\sqrt{2} \mathrm{r}_{0}\right)\right\} \mathrm{H} \\
& \mathrm{G}_{2}=2\left\{\left(-6-6 \rho_{0}-\rho_{0}^{2}+\rho_{0}^{3}\right) \phi\left(r_{0}\right)\right. \\
&\left.+\left(-3 \sqrt{2}-6 \rho_{0}-\sqrt{2} \rho_{0}^{2}+2 \rho_{0}^{3}\right) \phi\left(\sqrt{2} r_{0}\right)\right\} \mathrm{H} \\
& \mathrm{G}_{3}=2\left[\left\{\left(30+30 \rho_{0}+9 \rho_{0}^{2}-\rho_{0}^{3}-\rho_{0}^{4}\right) \phi\left(r_{0}\right)+(15 / 2) \sqrt{2}\right.\right. \\
&+\left.\left.\left.15 \rho_{0}+(9 / 2) \sqrt{2} \rho_{0}^{2}-\rho_{0}^{3}-\sqrt{2} \rho_{0}^{4}\right) \phi\left(\sqrt{2} r_{0}\right)\right\}\right] \mathrm{H} \\
& \mathrm{G}_{1,1}=\left\{\left(-3 \sqrt{2}-6 \rho_{0}-\sqrt{2} \rho_{0}^{2}+2 \rho_{0}^{3}\right) \phi\left(\sqrt{2} r_{0}\right)\right\} \mathrm{H} \\
& \mathrm{G}_{2,1}=(15 / 2) \sqrt{2}+15 \rho_{0}+(9 / 2) \sqrt{2} \rho_{0}^{2} \\
&\left.\left.-\rho_{0}^{3}-\sqrt{2} \rho_{0}^{4}\right) \phi\left(\sqrt{2} r_{0}\right)\right\} \mathrm{H} \\
& \mathrm{G}_{1,1,1}= 0
\end{aligned}
$$

Here, $\mathrm{x}=\mathrm{h} \omega_{0} / 2 \mathrm{~K}_{\mathrm{B}} \mathrm{T}, \omega_{0}^{2}=\left(\frac{1}{\mathrm{M}_{+}}+\frac{1}{\mathrm{M}_{-}}\right)\left(\frac{1}{\mathrm{H} b r_{0}}\right), \mathrm{K}_{\mathrm{B}}$ is Boltzmann's constant,

$\mathrm{H}=\left\{\left(\rho_{0}-2\right) \phi\left(r_{0}\right)+2\left(\rho_{0}-\sqrt{2}\right) \phi\left(\sqrt{2} r_{0}\right)\right\}^{-1}$ and values of lattice sums are:

$$
\begin{aligned}
& S_{3}^{(1)}=-0.58252 ; \mathrm{S}_{5}^{(2)}=-1.04622 ; \mathrm{S}_{5}^{(1,1)}=0.23185 \\
& S_{7}^{(3)}=-1.36852 ; \mathrm{S}_{7}^{(2,1)}=0.16115 ; \mathrm{S}_{7}^{(1,1,1)}=-0.09045
\end{aligned}
$$

The obtained results of SOEC and TOEC are used to find out the ultrasonic velocities and Grüneisen parameters for longitudinal and shear waves along different crystallographic directions. Those in turn are related to compute acoustic coupling constants and ultrasonic attenuation coefficient [20-23] as discussed in secondary 
phase of theory and discussion section.

The secondary objective of the present investigation is to develop a theory for evaluation of ultrasonic attenuation. Mason-Bateman Theory $[11,14,15,19-27]$ is still widely used successfully to study the ultrasonic attenuation at higher temperature $(\approx 300 \mathrm{~K})$ in solids. It is more reliable theory to study anharmonicity of the crystals as it involves elastic constants directly through acoustic coupling constant " $D$ " in the evaluation of ultrasonic attenuation $(\alpha)$. The thermoelastic loss and Akhiezer loss [24] under condition $\omega \tau \ll 1$ is given by:

$$
\begin{aligned}
& \alpha_{\mathrm{th}}=\left[\omega^{2}\left\langle\gamma_{\mathrm{i}}^{\mathrm{j}}\right\rangle^{2} \mathrm{kT}\right] / 2 \rho \mathrm{V}_{\mathrm{L}}^{5} \\
& \alpha_{\mathrm{Akh}}=\left[\mathrm{E}_{0} \mathrm{D} \omega^{2} \tau /\left(6 \rho \mathrm{V}^{3}\right)\right]
\end{aligned}
$$

where $\rho$ is the density; $\omega$ is angular frequency of ultrasonic wave; $\mathrm{k}$ is the thermal conductivity; $\mathrm{E}_{0}$ is the thermal energy; $\mathrm{V}$ is velocity of longitudinal and shear waves; $\mathrm{T}$ is the temperature in Kelvin scale; $\mathrm{L}$ and $\mathrm{S}$ represent longitudinal and shear waves. Grüneisen number $\gamma_{\mathrm{i}}^{\mathrm{j}}$ ( $\mathrm{i}$ is the mode of propagation and $\mathrm{j}$ is the direction of propagation) is related to SOEC and TOEC. The thermal relaxation time for longitudinal wave is twice that of shear wave.

$$
\tau=0.5 \tau_{\mathrm{L}}=\tau_{\mathrm{S}}=\left(3 \mathrm{k} / \mathrm{C}_{\mathrm{V}} \mathrm{V}_{\mathrm{D}}^{2}\right)
$$

where $C_{V}$ is the specific heat per unit volume and $V_{D}$ is the Debye average velocity. The acoustic coupling constant, which is measure of conversion of ultrasonic energy into thermal energy, can be obtained by:

$$
\mathrm{D}=9\left\langle\left(\gamma_{\mathrm{i}}^{\mathrm{j}}\right)\right\rangle^{2}-\left[3\left\langle\gamma_{\mathrm{i}}^{\mathrm{j}}\right\rangle^{2} \rho \mathrm{C}_{\mathrm{v}} \mathrm{T}\right] / \mathrm{E}_{0}
$$

\section{Results and Discussion}

The Transmission Electron Microscope (TEM) shows that the iron nanowires are highly uniform and exhibit a single crystal structure. The X-ray diffraction (XRD) patterns of iron nanowire arrays specified that most of the iron nanowire arrays have the obvious preferred orientation along the $<200>$ direction [28].

The ultrasonic attenuation due to different mechanism at high temperatures are evaluated using nearest neighbour distance $\left(r_{0}\right)=1.24 \AA$ and Born-Mayer (hardness) parameter $(b)=0.303 \AA$ for Fe. The SOEC and TOEC are calculated at different temperatures. The values of density are taken from the literature [29]. The microstructure of $\mathrm{Fe}$ was tested by transmission electron microscopy and $\mathrm{X}$-ray diffraction. The mean size was found between 100 and $200 \mathrm{~nm}$ [30].

The computed values of SOEC and TOEC at high temperatures are listed in Table 1. It is clear from Table 1 that, out of nine elastic constants, five (i.e., $\mathrm{C}_{11}, \mathrm{C}_{44}$, $\mathrm{C}_{111}, \mathrm{C}_{166}$ and $\mathrm{C}_{144}$ ) are increasing and three (i.e., $\mathrm{C}_{12}$, $\mathrm{C}_{112}$, and $\mathrm{C}_{123}$ ) are decreasing with the temperature while $\mathrm{C}_{456}$ is found to be unaffected. The increase or decrease in elastic constants is mainly due to two basic parameters i.e., lattice parameter and hardness parameter with other common parameters as shown in Equations (1)-(5).

This type of behaviour has already been found in materials like $\mathrm{Ce}, \mathrm{Yb}$ and $\mathrm{Th}$ [31]. Figure 1 shows that the

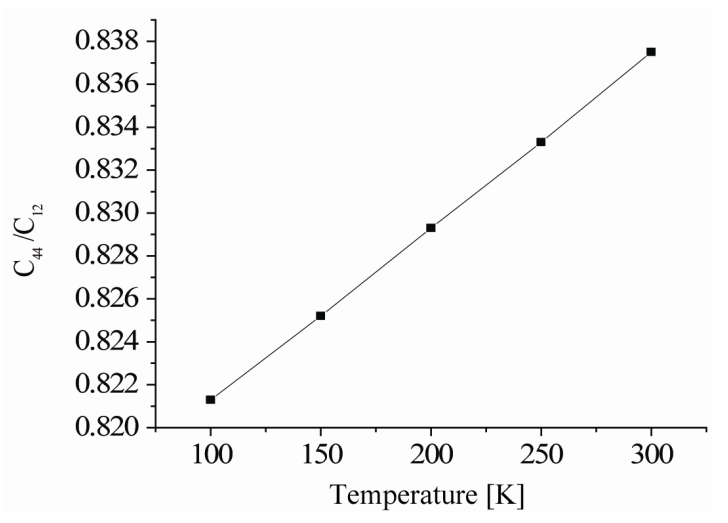

Figure 1. Temperature vs. $\mathrm{C}_{44} / \mathrm{C}_{12}$.

Table 1. SOEC and TOEC $\left(10^{11} \mathrm{~N} / \mathrm{m}^{2}\right)$ of Fe-metal in the temperature range $100-300 \mathrm{~K}$.

\begin{tabular}{ccccccccccc}
\hline Temp.[K] & $\mathrm{C}_{11}$ & $\mathrm{C}_{12}$ & $\mathrm{C}_{44}$ & $\mathrm{C}_{111}$ & $\mathrm{C}_{112}$ & $\mathrm{C}_{123}$ & $\mathrm{C}_{144}$ & $\mathrm{C}_{166}$ & $\mathrm{C}_{456}$ \\
\hline 100 & 1.8261 & 0.6918 & 0.5682 & -20.6498 & -0.7016 & 0.4734 & 0.4785 & -0.7376 & 0.4441 \\
150 & 1.8270 & 0.6903 & 0.5697 & -20.5068 & -0.6564 & 0.4964 & 0.5042 & -0.7104 & 0.4526 \\
200 & 1.8280 & 0.6887 & 0.5712 & -20.3637 & -0.6112 & 0.5195 & 0.5299 & -0.6832 & 0.4611 \\
250 & 1.8289 & 0.6872 & 0.5727 & -20.2206 & -0.5659 & 0.5426 & 0.5555 & -0.6560 & 0.4695 \\
300 & 1.8299 & 0.6856 & 0.5742 & -20.0776 & -0.5207 & 0.5657 & 0.5812 & -0.6288 & 0.4780 \\
\hline
\end{tabular}


temperature dependence of $\mathrm{C}_{44} / \mathrm{C}_{12}$ for Iron. For Iron, we have the deviation from the Cauchy relation on increaseing the temperature. That is the result indicates that the dominance of ionic interaction decreases with the temperature. On the other hand although still from the condition $\mathrm{C}_{44} / \mathrm{C}_{12}=1$, the result for Iron suggests that the bonding become more ionic with increase in temperature.

The stability of cubic crystals is expressed in terms of elastic constants as $\mathrm{B}_{\mathrm{T}}=\left(\left(\mathrm{C}_{11}+2 \mathrm{C}_{12}\right) / 3\right)>0, \mathrm{C}_{44}>0$ and $\mathrm{C}_{\mathrm{S}}=\left(\left(\mathrm{C}_{11}-\mathrm{C}_{12}\right) / 2>0\right), \mathrm{C}_{\mathrm{IJ}}$ are conventional elastic constants, $\mathrm{B}_{\mathrm{T}}$ is the bulk modulus. The quantize $\mathrm{C}_{44}$ and $\mathrm{C}_{\mathrm{S}}$ are the shear and tetragonal moduli of a cubic crystal. Estimated values of bulk and tetragonal moduli for BkY are presented in Figure 2. These conditions are also known as Born criterion of mechanical stability. The Born criterion of mechanical stability in case of iron is satisfied as shown in Figure 2. Hence our approach to compute SOEC/TOEC is correct.

The values of SOEC at $300 \mathrm{~K}$ are $\mathrm{C}_{11}=1.8299 \times 10^{11}$ $\mathrm{N} / \mathrm{m}^{2}, \mathrm{C}_{12}=0.6856 \times 10^{11} \mathrm{~N} / \mathrm{m}^{2}$ and $\mathrm{C}_{44}=0.5742 \times 10^{11}$ $\mathrm{N} / \mathrm{m}^{2}$ and the experimental values at $300 \mathrm{~K}$ are $\mathrm{C}_{11}=$ $2.37 \times 10^{11} \mathrm{~N} / \mathrm{m}^{2}, \mathrm{C}_{12}=1.41 \times 10^{11} \mathrm{~N} / \mathrm{m}^{2}$ and $\mathrm{C}_{44}=$ $1.160 \times 10^{11} \mathrm{~N} / \mathrm{m}^{2}$ of $\mathrm{Fe}$ at normal grain size [32]. Although SOECs of the nanosized metals are smaller than the normal sized metal, but quanta of SOECs are same.

Thermal relaxation time $\left(\tau_{\mathrm{th}}\right)$ is determined utilizing lattice thermal conductivity values [33-35]. Specific heat per unit volume $\left(\mathrm{C}_{\mathrm{v}}\right)$ and energy density $\left(\mathrm{E}_{0}\right)$ of crystals have been evaluated as a function of $\theta_{\mathrm{D}} / \mathrm{T}$ [29]; where $\theta_{\mathrm{D}}$ is Debye temperature. Non-linearity constant (D) are obtained at different temperature. The values of density $(\rho)$, specific heat $\left(\mathrm{C}_{\mathrm{v}}\right)$, energy density $\left(\mathrm{E}_{0}\right)$, longitudinal $\left(\mathrm{V}_{\mathrm{L}}\right)$, shear $\left(\mathrm{V}_{\mathrm{S}}\right)$ and Debye average velocity $(\overline{\mathrm{V}})$ are presented in Table 2. The values of thermal conductivity $(\mathrm{K})$, thermal relaxation time $\left(\tau_{\mathrm{th}}\right)$ and anisotropy are presented in Figure $\mathbf{3}$ and the values of non-linearity con- stants (acoustic coupling constants D) are presented in Table 3.

It is seen from Figure 3 that thermal relaxation time $\left(\tau_{\mathrm{th}}\right)$ decreases with temperature due to their thermal conductiveity values. It is also obvious from Figure 3 that the values of anisotropy in Fe are almost same at different tem-

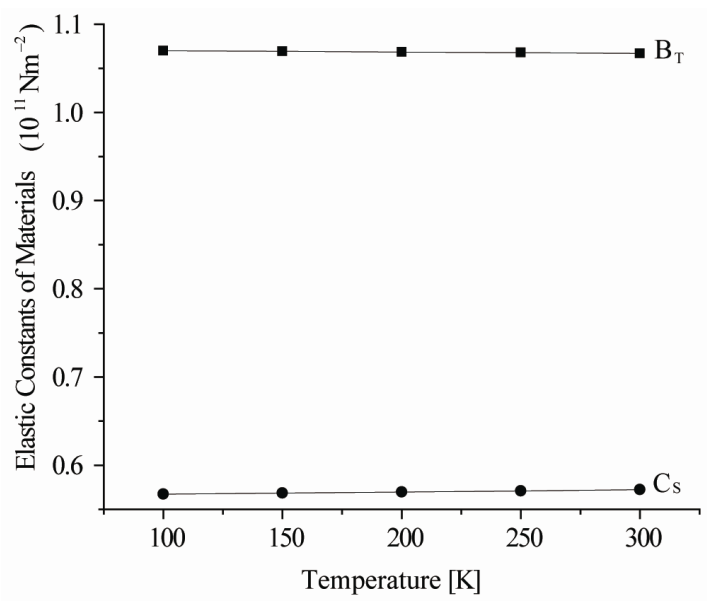

Figure 2. Temperature variation of $B_{T}$ and $C_{S}$.

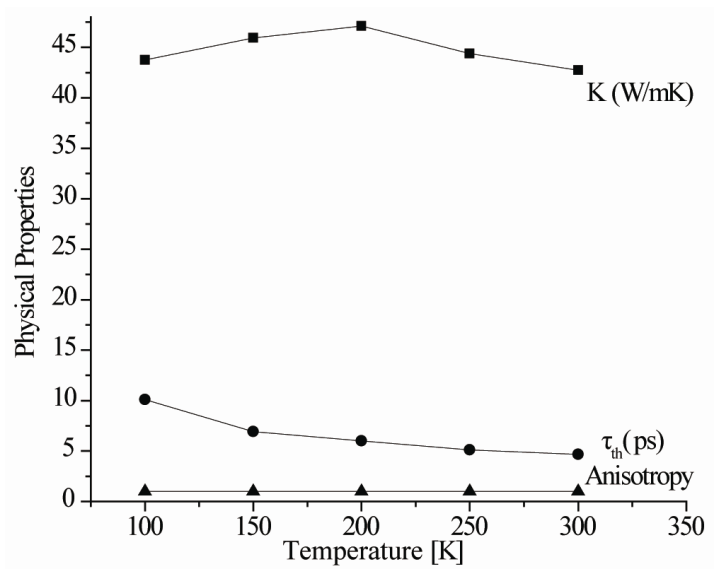

Figure 3. Temperature variation of $K, T_{S}$, Anisotropy.

Table 2. Density $(\rho)$ in $\mathrm{Kg} / \mathrm{m}^{3}$, specific heat $\left(C_{v}\right)$ Joule $/ \mathrm{m}^{3} \mathrm{~K}$, energy density $\left(E_{0}\right) \mathrm{Joule} / \mathrm{m}^{3}$, longitudinal, shear and Debye average velocity $(\bar{V}) 10^{3} \mathrm{~m} / \mathrm{sec}$ of Fe in the temperature range $100-300 \mathrm{~K}$.

\begin{tabular}{cccccccc}
\hline Temp. $[\mathrm{K}]$ & $\rho$ & $\mathrm{C}_{\mathrm{v}}$ & $\mathrm{E}_{0}$ & $\mathrm{~V}_{\mathrm{L}}$ & $\mathrm{V}_{\mathrm{S}}$ & $\overline{\mathrm{V}}$ \\
\hline 100 & 7.96 & 1.449 & 0.4790 & 4.790 & 2.672 & 2.937 \\
150 & 7.93 & 2.296 & 1.4430 & 4.800 & 2.680 & 2.947 \\
200 & 7.91 & 2.701 & 2.6227 & 4.807 & 2.687 & 2.954 \\
250 & 7.89 & 2.973 & 4.1002 & 4.815 & 2.694 & 2.961 \\
300 & 7.87 & 3.113 & 5.6162 & 4.822 & 2.701 & 2.969 \\
\hline
\end{tabular}


Table 3. Acoustic coupling constants (DL for longitudinal wave, DS for shear wave), along $<100>$, $<110>$ and $<111>$ crystallographic directions of $\mathrm{Fe}$ in the temperature range $100-300 \mathrm{~K}$.

\begin{tabular}{|c|c|c|c|c|c|c|}
\hline \multicolumn{2}{|c|}{ Temperature $[\mathrm{K}] \rightarrow$} & \multirow{2}{*}{100} & \multirow{2}{*}{150} & \multirow{2}{*}{200} & \multirow{2}{*}{250} & \multirow{2}{*}{300} \\
\hline Direction $\downarrow$ & Parameter $\downarrow$ & & & & & \\
\hline \multirow{2}{*}{$<100>$} & $\mathrm{D}_{\mathrm{L}}$ & 7.308 & 7.256 & 7.186 & 7.113 & 7.038 \\
\hline & $\mathrm{D}_{\mathrm{S}}$ & 0.648 & 0.662 & 0.676 & 0.691 & 0.706 \\
\hline \multirow{3}{*}{$<110>$} & $\mathrm{D}_{\mathrm{L}}$ & 12.085 & 12.096 & 12.017 & 11.914 & 11.790 \\
\hline & $\mathrm{D}_{\mathrm{S}}{ }^{*}$ & 0.749 & 0.769 & 0.790 & 0.811 & 0.833 \\
\hline & $\mathrm{D}_{\mathrm{S}}{ }^{* *}$ & 12.142 & 11.964 & 11.788 & 11.614 & 11.442 \\
\hline \multirow{2}{*}{$<111>$} & $\mathrm{D}_{\mathrm{L}}$ & 14.405 & 14.370 & 14.041 & 13.627 & 13.169 \\
\hline & $\mathrm{D}_{\mathrm{S}}{ }^{* * *}$ & 15.459 & 15.133 & 14.804 & 14.485 & 14.178 \\
\hline
\end{tabular}

* Shear wave polarized along $<001>$ direction, ${ }^{* *}$ Shear wave polarized along $<1 \overline{1} 0>$ direction, ${ }^{* * *}$ Shear wave polarized along $<\overline{1} 10>$ direction.

peratures. The ultrasonic attenuation coefficients $\left(\alpha / \mathrm{f}^{2}\right)_{\text {Akh. }}$. due to $\mathrm{p}$-p interaction and $\left(\alpha / \mathrm{f}^{2}\right)_{\text {th. }}$ due to thermoelastic relaxation in nanosized $\mathrm{Fe}$ at $100-300 \mathrm{~K}$ along $<100>$, $<110>$ and $<111>$ crystallographic directions are determined and the temperature variation of the attenuation is shown in Figures 4-6. A perusal of the Figures 4-6 shows that the thermoelastic loss $\left(\alpha / \mathrm{f}^{2}\right)_{\text {th. }}$ is negligible in comparison to the Akhiezer type attenuation (loss due to p-p interaction).

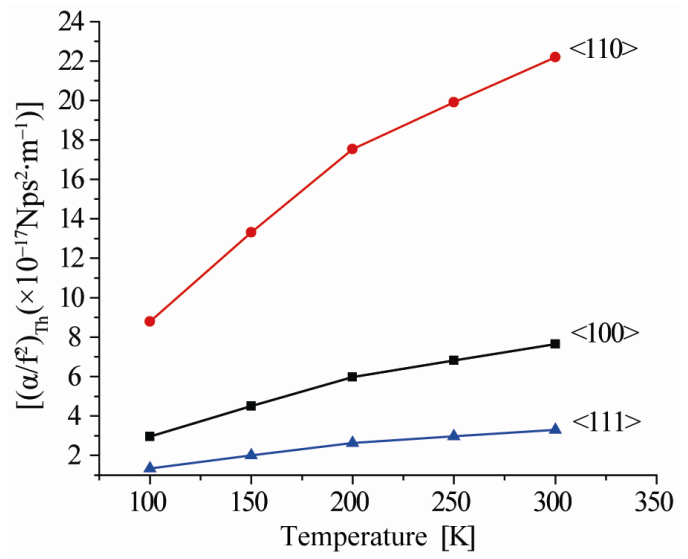

Figure 4. $\left[\left(\alpha / f^{2}\right)_{\mathrm{Th}}\left(\times 10^{-17} \mathrm{Nps}^{2} \cdot \mathrm{m}^{-1}\right)\right]$ vs. Temperature of Fe.

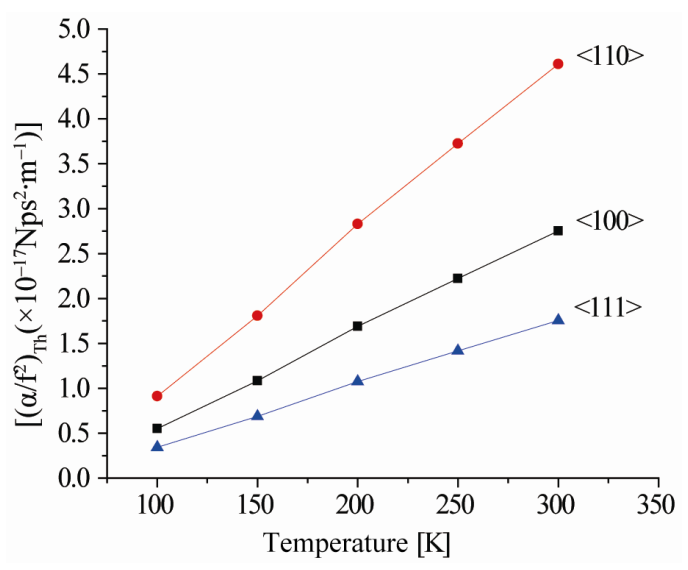

Figure 5. $\left[\left(\alpha / \mathrm{f}^{2}\right)_{\text {Akh.long. }}\left(\times 10^{-16} \mathrm{Nps}^{2} \cdot \mathrm{m}^{-1}\right)\right]$ vs. Temperature of Fe.

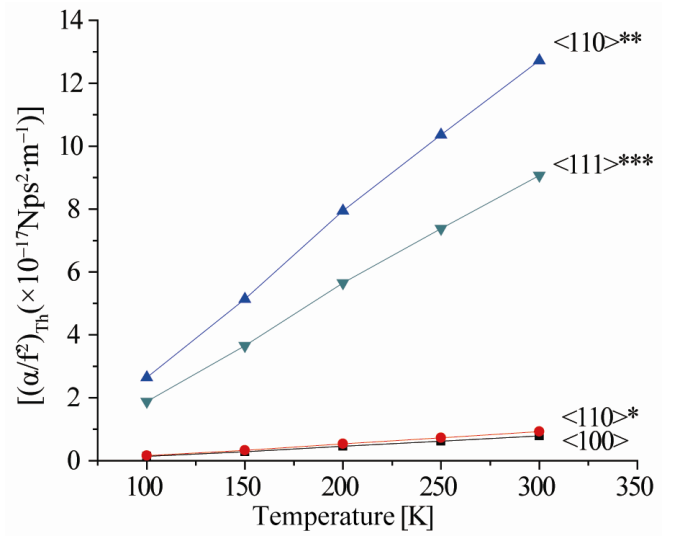

Figure 6. $\left[\left(\alpha / \mathrm{f}^{2}\right)_{\mathrm{Akh} . S h e a r .}\left(\times 10^{-16} \mathrm{Nps}^{2} \cdot \mathrm{m}^{-1}\right)\right]$ vs. Temperature of Fe.

This is due to low values of thermal conductivity and higher values of Debye average velocities of the wave along all the three propagating directions. There is positive temperature dependence of the ultrasonic attenuation at high temperatures as in other metals [36,37]. This positive temperature dependence of ultrasonic absorption is due to the fact that $p-p$ interaction occurs at high temperatures mainly at room temperature. Order of attenuation in the nanosized $\mathrm{Fe}$ for longitudinal wave and shear wave is the same as in the like metals [38].

Attenuation of longitudinal wave is more than that of shear wave along $<100\rangle$ and $\langle 110\rangle$ direction polarized along $<001>$ direction. A greater value of ultrasonic attenuation for longitudinal wave along $<100>$ in comparison to shear wave attenuation is due to greater value of non-linearity constants $\left(\mathrm{D}_{\mathrm{L}}\right)$. In case of wave propagating along $\langle 110\rangle$ direction and polarized along $<001\rangle$, although $\mathrm{D}_{\mathrm{S}}{ }^{*}$ is greater than the $\mathrm{D}_{\mathrm{L}}$, the values of $\left(\alpha / \mathrm{f}^{2}\right)_{\text {Akh.long. }}$ are greater than the $\left(\alpha / \mathrm{f}^{2}\right)_{\text {Akh.shear. This be- }}$ haviour is due to smaller value of $\mathrm{C}_{44}$ (SOEC) in compareson to $\mathrm{C}_{11}$ affecting the wave velocity as per their relations as given below $\mathrm{V}_{\text {longitudinal }}=\sqrt{\mathrm{C}_{11} / \rho}$ and $\mathrm{V}_{\text {shear }}=\sqrt{\mathrm{C}_{44} / \rho}$, here $\rho$ is the density of the material.

In the case of the wave propagating along $<111>$ and 
shear wave polarized along $<\overline{1} 10>$; shear attenuation $\left(\alpha / \mathrm{f}^{2}\right)_{\text {Akh.shear }}{ }^{* * *}$ is greater than the longitudinal wave attenuation $\left(\alpha / \mathrm{f}^{2}\right)_{\text {Akh.long. }}$ This is due to greater value of shear wave non-linearity constants $\mathrm{D}_{\mathrm{S}}{ }^{* * *}$ in comparison to longitudinal wave non-linearity constants $\mathrm{D}_{\mathrm{L}}$. Although no experimental values of attenuation in $\mathrm{Fe}$ (bcc) are available for the comparison, but order of attenuation is found same as other bcc metals like potassium, which is studied experimentally by Sathish et al. [39].

Since whole computation is based on only two basic parameters i.e. lattice parameter and hardness parameter, one may conclude that the behaviour of temperature dependence of ultrasonic absorption and other allied parameters of nanosized $\mathrm{Fe}$ is particular one for the material and supports our theoretical approach.

The preliminary results obtained in this work can be used for further experimental investigation with the pulse echo overlap (PEO) technique for ultrasonic measurements. The application of this measurement is mainly in non-destructive testing (NDT) of a material with conventional analytical techniques such as polarising microscopy, X-ray diffraction (XRD), surface tension analysis, solid state nuclear magnetic resonance (NMR), scanning electron microscopy (SEM) and transmission electron microscopy (TEM).

\section{References}

[1] P. A. Elmore and M. A. Breazeale, "Dispersion and Frequency Dependent Nonlinearity in a Graphite-Epoxy Composite," Ultrasonics, Vol. 41, No. 9, 2004, pp. 709-718. doi:10.1016/j.ultras.2003.11.001

[2] D. M. Profunser, J. Vollmann and J. Dual, "Determination of the Material Properties of Microstructures by Laser Based Ultrasound," Ultrasonics, Vol. 42, No. 1-9, 2004, pp. 641-646.

[3] H. Ogi, A. Tsujimoto, S. Nishimura and M. Hirao, "Acoustic study of Kinetics of Vacancy Diffusion toward Dislocations in Aluminum," Acta Materialia, Vol. 53, No. 2, 2005, pp. 513-517. doi:10.1016/j.actamat.2004.10.007

[4] R. P. Singh and G. S. Verma, "Phonon Conductivity and Acoustic Attenuation in Si," Physical Review, Vol. 171, No. 3, 1968, pp. 838-842. doi:10.1103/PhysRev.171.838

[5] K. J. Singh, Y. Matsuda, K. Hattori, H. Nakamo and S. Nagai, "Non-Contact Sound Velocities and Attenuation Measurements of Several Ceramics at Elevated Temperatures", Ultrasonics, Vol. 41, No. 1, 2003, pp. 9-14. doi:10.1016/S0041-624X(02)00392-X

[6] R. Esquivel-Sirvent, B. Tan, I., Abdelraziq, S. S. Yun and F. B. Stumpf, "Absorption and Velocity of Ultrasound in Binary Solutions of Poly (Ethylene Glycol) and Water," Journal of the Acoustical Society of America, Vol. 93, No.2, 1993, pp. 819-820. doi:10.1121/1.405444

[7] S. K. Kor and S. C. Deorani, "Correlation between Acoustic and Dielectric Relaxation Times in Liquids," Physical
Review Letters, Vol. 27, No. 5, 1971, pp. 242-244. doi:10.1103/PhysRevLett.27.24

[8] S. K. Kor and S. K. Pandey, "Ultrasonic Investigation of Cholesteric Liquid Crystals," Journal of Chemical Physics, Vol. 64, No. 4, 1976, pp. 1333-1336. doi:10.1103/PhysRevLett.27.24

[9] S. K. Kor, R. R. Yadav and D. Singh, "Ultrasonic Studies of CTAB in Glycol," Molecular Crystals Liquid Crystals, Vol. 392, No. 1, 2002, pp. 75-81. doi:10.1080.15421400390193918

[10] W. P. Mason, "Piezielectric Crystals and Their Application to Ultrasonics," D. Van Nostrand Co. Inc. Princeton, New Jersey, 1950.

[11] W. P. Mason, "Physical Acoustics," Vol. IIIB, Academic Press, New York, 1965.

[12] D. Singh, P. K. Yadawa and S. K. Sahu, "Effect of Electrical Resistivity on Ultrasonic Attenuation in NpTe," Cryogenics, Vol. 50, No. 8, 2010, pp. 476-479. doi:10.1103/PhysRevLett.27.24

[13] D. Singh, D. K. Pandey, P. K. Yadawa and A. K. Yadav, "Attenuation of Ultrasonic Waves in $\mathrm{V}, \mathrm{Nb}$ and $\mathrm{Ta}$ at Low Temperature," Cryogenics, Vol. 49, No. 1, 2009, pp. 1216. doi:10.1016/j.cryogenics.2008.08.008

[14] D. Singh, D. K. Pandey, D. K. Pandey and R. R. Yadav, "Propagation of Ultrasonic waves in Neptunium Monochalcogenides," Applied Acoustics, Vol. 72, No. 10, 2011, pp. 737-741. doi:10.1016/j.apacoust.2011.04.002

[15] D. Singh and D. K. Pandey, "Ultrasonic Investigations in Intermetallics," Pramana-Journal of Physics, Vol. 72, No. 2, 2009, pp. 389-398. doi:10.1007/s12043-009-0034-7

[16] K. Brugger, "Thermodynamic Definition of Higher Order Elastic Coefficients," Physical Review, Vol. 133, 1964, pp. A1611-A1612. doi:10.1103/PhysRev.133.A1611

[17] M. Born and J. E. Mayer, "Zur Gittertheorie der Lonenkristalle," Zeitschrift für Physik, Vol. 75, No. 1-2, 1932, pp. 1-18. doi:10.1007/BF01340511

[18] P. B. Ghate, "Third-Order Elastic Constants of Alkali Halide Crystals," Physical Review, Vol. 139, No. 5A, 1965, pp. 1666-1674. doi:10.1103/PhysRev.139.A1666

[19] S. Mori Y. Hiki, "Calculation of the Third- and FourthOrder Elastic Constants of Alkali Halide Crystals," Journal of the Physical Society of Japan, Vol. 45, No. 5, 1975, pp. 1449-1456. doi:10.1143/JPSJ.45.1449

[20] R. P. Singh and R. K. Singh, "Theoretical Study of Temperature Dependent Lattice Anharmonicity in $\mathrm{TlCl}$ and TlBr," Current Applied Physics, Vol. 10, No. 4, 2010, pp. 1053-1058. doi:10.1016/j.cap.2009.12.040

[21] R. P. Singh and R. K. Singh, "Temperature Dependent Physiccal Effects of Ultrasonic Waves in Beryllium Chalcogenides," Applied Acoustics, Vol. 71, No. 11, 2010, pp. 328-334. doi:10.1016/i.apacoust.2009.10.005

[22] J. Kumar, Kailash, V. Kumar and A. K. Choudhary, "Temperature Dependent of Higher Order Elastic Constants of TeO Crystal," Asian Journal of Chemistry, Vol. 23, No. 12, 2011, pp. 5601-5604.

[23] J. Kumar, Kailash, S. K. Shrivastava, D. Singh and V. Ku- 
mar, "Ultrasonic Attenuation in Calcium Oxide," Advances in Materials Physics and Chemistry, Vol. 1, No. 2, 2011, pp. 44-49. doi:/10.4236/ampc.2011.12008

[24] A. Akhiezer, "On the Absorption of Sound in Solids," Journal of Physics (Moscow), Vol. 1, No.1, 1939, pp. 277-287.

[25] H. E. Bömmel and K. Dransfeld, "Excitation and Attenuation of Hypersonic Waves in Quartz," Physical Review, Vol. 117, No. 5, 1960, pp. 1245-1252. doi:10.1103/PhysRev.117.1245

[26] T. O. Woodruff and H. Ehrenreich, "Absorption of Sound in Insulators," Physical Review, Vol. 123, No. 5, 1961, pp. 1553-1559. doi:10.1103/PhysRev.123.1553

[27] W. P. Mason and T. B. Bateman, "Relation between ThirdOrder Elastic Moduli and the Thermal Attenuation of Ultrasonic Waves in Nonconducting and Metallic Crystals," Journal of the Acoustical Society of America, Vol. 40, No. 4, 1966, pp. 852-862. doi:org/10.1121/1.1910158

[28] Y. L. Sun, Y. Dai, L. Q. Zhou and W. Chen, "SingleCrystal Iron Nanowire Arrays," Solid State Phenomena, Vol. 121-123, No. 3, 2007, pp. 17-20. doi:10.4028/www.scientific.net/SSP.121-123.17

[29] D. E. Gray, Ed., "AIP Handbook," 3rd Edition, Mc-Graw Hill Book Co. Inc., New York, 1965.

[30] K. Pekala and M. Pekala, "Low Temperature Transport Properties of Nanocrystalline $\mathrm{Cu}, \mathrm{Fe}$ and Ni," Nanostructured Materials, Vol. 6, No. 3, 1995, pp. 819-822. doi:10.1016/0965-9773(95)00185-9

[31] R. R. Yadav, D. Singh and A. K. Tiwari, "Ultrasonic Evaluation in Rare-Earth Metals," Journal of the Acoustical Society of India, Vol. 30, No. 1-2, 2002, pp. 59-63.

[32] L. A. Girifalco and V. G. Weizer, "Application of the Morse
Potential Function to Cubic Metals," Physical Review, Vol. 114, No. 3, 1959, pp. 687-690.

doi:10.1103/PhysRev.114.687

[33] Y. S. Touloukian, et al., "Thermal Conductivity: Metallic Elements and Alloys," TPRS Series, Vol. I, IFI/Plenum, New York, 1970.

[34] P. Haen and G. T. Meaden, "The Thermal Conductivity, Thermoelectric Power, and Electrical Resistivity of Thorium between 5 and $100^{\circ} \mathrm{K}$," Cryogenics, Vol. 5, No. 4, 1965, pp. 194-198. doi:10.1016/0011-2275(65)90056-1

[35] M. A. Gurry, S. Legvold and F. H. Spedding, "Electrical Resistivity of Europium and Ytterbium," Physical Review B, Vol. 117, No. 4, 1960, pp. 953-954. doi:10.1103/PhysRev.117.953

[36] S. K. Kor, Kailash, K. Shanker and P. Mehrotra, "Behaviour of Acoustical Phonons in Metals in Low Temperature Region," Journal of the Physical Society of Japan, Vol. 56, No. 7, 1987, pp. 2428-2432. doi:10.1143/JPSJ.56.2428

[37] S. K. Kor and R. R. Yadav, "Ultrasonic Attenuation Due to Electron-Phonon Interaction in Palladium," Journal of Pure and Applied Ultrasonics, Vol. 8, No. 3, 1986, pp. 89-90.

[38] S. K. Kor and R. K. Singh, "Ultrasonic Attenuation in Alkali Metals," Acustica, Vol. 79, No. 2, 1993, pp. 292-295.

[39] S. Sathish, S. Chaterjee, O. N. Awasthi and E. S. R. Gopal, "Electron-Electron Scattering and Ultrasonic Attenuation in Potassium," Journal of Low Temperature Physics, Vol. 63, No. 5-6, 1986, pp. 423-429. doi:10.1007/BF00681490 